UDC 316.346.32-053.9

LBC 60.542.18

\title{
SPECIAL ASPECTS OF SELF-PRESERVATION BEHAVIOR FORMATION OF ELDERLY PEOPLE: RECORD OF SOCIOLOGICAL ANALYSIS
}

\author{
Lyubov A. Leshchenko \\ Volgograd Institute of Management, Branch of the Russian Academy of National Economy \\ and Public Service under the President of Russia, Volgograd, Russian Federation
}

\begin{abstract}
The problem of an aging population is reflected in the writings of philosophers and sociologists. The author identifies the scientific thought of two stages for the study of the characteristics of the phenomenon of old age: an early (philosophical), late (sociological) period. At the initial stage of theoretical thinking the question about the social significance and the role of the elderly is analyzed in the works of ancient thinkers (Aristotle, Plato, Senac, etc.) where the old age is seen as "a special state of mind" and as "greed", "loss of youth and strength". During the late or sociological period (V. Henry, Ch. Tobin, K. Cards etc.) the socio-economic status of the elderly in society was studied. Describing modern social setup, the old age in the minds of individuals, is increasingly interpreted as a "natural disease" or "infirmity". Consequently the purpose of this article is to study the process of forming of selfpreservation behavior in the elderly. The author of the article esees the self-preservation behavior as a private attitude of the individual concerning preservation and maintenance of health. It was revealed that the adoption of the medical status of the service, impact of media, the existence of social stereotypes contribute to the taking of adverse (negative) model of self-preservation behavior by the elderly. The article noted that the most important task of modern society should be introducing the concept of "healthy ageing" or "youthful old age" in consciousness of people.

Key words: old age, elderly people, healthy aging, healthy aging, self-preserving behavior, models of selfpreserving behavior.
\end{abstract}

УДК 316.346.32-053.9

ББК 60.542 .18

\section{ОСОБЕННОСТИ ФОРМИРОВАНИЯ \\ САМОСОХРАНИТЕЛЬНОГО ПОВЕДЕНИЯ У ЛИЦ ПОЖИЛОГО ВОЗРАСТА: ОПЫТ СОЦИОЛОГИЧЕСКОГО АНАЛИЗА}

\author{
Любовь Александровна Лещенко \\ Волгоградский институт управления - филиал Российской академии народного хозяйства \\ и государственной службы при Президенте России, г. Волгоград, Российская Федерация
}

\begin{abstract}
Аннотация. Проблема старения населения традиционно находит свое отражение в трудах философов и социологов. Соответственно в научно-теоретической мысли выделяются два этапа (подхода) к изучению особенностей феномена старости: ранний (философский) и поздний (социологический). На первоначальном этапе рассуждения о социальной значимости и роли лиц пожилого возраста содержатся в трудах антич․ ных мыслителей (Аристотель, Платон, Сенека и др.), где старость, с одной стороны, рассматривается как 궁 особое состояние души, а с другой - как утрата молодости и сил. Для позднего или социологического \& периода (В. Генри, Ш. Тобин, К. Карт и др.) характерным является изучение социально-экономического положения лиц пожилого возраста в обществе. С точки зрения современных общественных установок старость в сознании индивидов все чаще интерпретируется как «естественная болезнь» или «немощность». В связи с этим целью данной статьи является изучение особенностей процесса формирования самосохранительного поведения у лиц пожилого возраста. Под самосохранительным поведением автор понимает лично(9) стне установки индивида в отношении сохранения и поддержания здоровья. Было выявлено, что принятию
\end{abstract}


лицами пожилого возраста негативной (отрицательной) модели самосохранительного поведения способствует отношение к медицине как услуге, влияние средств массовой информации, существование общественных стереотипов. Автор статьи приходит к выводу, что важнейшей задачей современного общества должно стать внедрение в сознание людей модели «здоровой старости».

Ключевые слова: старость, лица пожилого возраста, здоровое старение, самосохранительное поведение, модели самосохранительного поведения.

В последние десятилетия доля пожилых людей от общей численности населения постоянно растет. По прогнозам Всемирной организации здравоохранения, за период с 2015 по 2025 г. доля лиц старше 60 лет увеличится с 12 до $22 \%$ [5]. В связи с возникшей социально-демографической ситуацией старость в сознании людей все чаще понимается как «естественная болезнь», которая оказывает негативное влияние на все сферы общественной жизни (см. таблицу).

Вопрос о сущности и природе старости нашел свое отражение в работах древнегреческих философов и не теряет своей актуальности. В научно-теоретической мысли условно можно выделить два периода в изучении сущности старости: ранний (философский) и поздний (социологический).

Ранний (философский) период. В трудах древнегреческого философа Аристотеля старость рассматривается как период, во время которого людей покидают физические, умственные силы, духовные способности [4]. В свою очередь Сенека разделяет человеческую жизнь на четыре периода: «младенчество», «детство», «отрочество» и «старость». По его мнению, в период старости появляется возрастная усталость, а не немощность [4]. Более рациональное понимание старости дается в период Нового времени в работах Ф. Бэкона и Т. Гоббса, где старость как жизненный период рассматривается, с одной стороны, как физическое увядание, а с другой - как особое состояние души [4].

Поздний (социологический) период. Первые теории, связанные с изучением особенностей процесса старения, находят свое отражение в социологической мысли 60-х гг. $\mathrm{XX}$ столетия, где превалировала идея о том, что последствия индустриальной революции и развитие национальных государств имели отрицательные последствия для лиц пожилого возраста. По мере того как производственный труд перемещался из дома на фабрики, люди пожилого возраста оказались в зоне риска, которая отражалась на их экономической независимости и активности. Таким образом, первые социологические теории были сосредоточены на изучении особенностей адаптации пожилых людей к ситуации приобретения нового социально-экономического статуса и положения. Так, согласно теории «старения как уменьшения обязательств», представленной в трудах американских исследователей Э. Каммингома и В. Генри, старость рассматривается как отстранение индивида от активной социальной жизни и общества в целом: «...ослабление взаимодействий между стареющими индивидами и обществом сформировалось как универсальный процесс, который освобождает пожилых от давления социальных институтов и соблюдения социальных норм, что облегчает переход от жизни к смерти» [8]. Большинство ученых-социологов, про-

\section{Влияние старения населения на общественные сферы}

\begin{tabular}{|l|l|}
\hline $\begin{array}{c}\text { Сфера обществен- } \\
\text { ной жизни }\end{array}$ & \multicolumn{1}{|c|}{ Содержание последствий старения населения } \\
\hline Экономическая & $\begin{array}{l}\text { - ухудшение трудовой структуры населения; } \\
\text { - увеличение среднего возраста занятого населения }\end{array}$ \\
\hline Социальная & $\begin{array}{l}\text { - ухудшение возрастной структуры населения; } \\
\text { - формирование более узкой базы для развития про- } \\
\text { цесса рождаемости населения; } \\
\text { - рост численности населения, которое нуждается в } \\
\text { поддержке со стороны государства; } \\
\text { - увеличение бюджетных расходов на социальное } \\
\text { обеспечение престарелых }\end{array}$ \\
\hline
\end{tabular}


Л.А. Лещенко. Особенности формирования самосохранительного поведения у лиц пожилого возраста

водивших свои исследования на рубеже 60 70-х гг. XX в., признавали, что уход пожилых людей от активной социальной жизни не является универсальной социальной закономерностью или нормальной составляющей социального процесса. В частности, в трудах Б. Ньюгартен и Ш. Тобина изоляция и отказ от социальной активности не являются естественными процессами в ходе старения [9]. Психологические и социальные потребности в пожилом возрасте не имеют существенных отличий от потребностей людей молодого и среднего возраста. В исследовании Ч. Лонгино и К. Карта главным показателем социальной активности и удовлетворенности жизнью в пожилом возрасте является сохранение и поддержание тесной связи с обществом и близким окружением (родственники, друзья) [10].

Таким образом, на современном этапе развития научной мысли под термином «старость» исследователи понимают:

- заключительный период жизни, характеризующийся ограничением приспособительных возможностей организма и морфологическими изменениями в различных системах и органах;

- биологический феномен, который сопровождается серьезными психологическими изменениями [6, с. 22];

- результат ограничения возможностей механизмов саморегуляции, проявляющихся в снижении возможностей компенсации первич- ных изменений в регулировании генетических процессов.

Исходя из определений следует, что старение - это необратимый, последовательный, физиологический процесс, который отражается на биологическом, социальном и психологическом уровне. В представленной ниже аналитической схеме показаны ключевые фазы процесса старения (см. рисунок).

На данном рисунке под буквенными обозначениями (А, Б, В) мы будем понимать поэтапную смену фаз старения. Так, фаза $\mathbf{A}$ (биологический уровень) подразумевает физиологические изменения в силу возрастных особенностей. Несмотря на значимость существующей проблемы, в современной научной литературе не существует единой возрастной периодизации старости. В силу указанной причины мы будем основываться на хронобиологической периодизации, которая была принята в 1963 г. Всероссийской организацией здравоохранения, согласно которой:

- пожилой возраст - 60-74 года;

- старческий возраст - 75-90 лет;

- долголетие - 90 лет [3, с. 25].

Фаза Б (социальный уровень) - второй элемент процесса старения, который предполагает, что в силу возрастных особенностей, физиологических изменений снижается уровень социальной активности, а это приводит к изменению социального статуса и положения. Для современного общества характерен стереотип,

A

БИОЛОГИЧЕСКИЙ УРОВЕНЬ

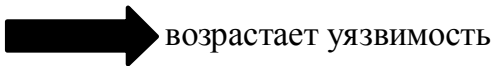

организма в силу возрастных

особенностей

Б

СОЦИАЛЬНЫЙ УРОВЕНЬ

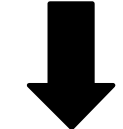

изменение социального

статуса и положения

B

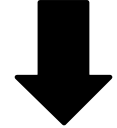

ПСИХОЛОГИЧЕСКИЙ УРОВЕНЬ

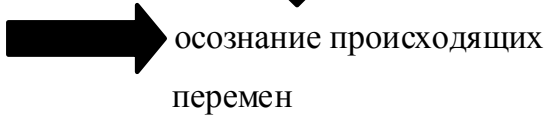

Фазы процесса старения 
согласно которому старость рассматривается как немощность, бесполезность, что оказывает влияние на социальную активность и поведение пожилых людей. По мнению Е.В. Щаниной, социальная активность зависит как минимум от четырех показателей: социально-экономического положения индивида; уровня состояния здоровья; социальной среды и личностных отношений между родственниками [7, с. 61].

Фаза В (психологический уровень) является результатом воздействия биологического и социального уровня, в ходе которого индивид, достигший пожилого возраста, осознает и адаптируется к социально-экономическим изменениям, а также к новым моделям поведения.

Для успешного прохождения фаз старения (биологической, социальной, психологической) индивид должен обладать определенным набором знаний, умений и навыков, которые будут способствовать поддержанию жизненного долголетия. В социологии тема, связанная с изучением сохранения и продления жизни индивидов, занимает одно из центральных мест и связана с использованием понятия «самосохранительное поведение». На современном этапе научной мысли под самосохранительным поведением понимают «систему действий и установок личности, направленных на сохранение здоровья и продление жизни» [2, с. 24]. В частности, специалисты в области демографии рассматривают самосохранительное поведение как систему целенаправленных действий, направленных на сохранение (положительная модель) или ухудшение (отрицательная модель) здоровья в течение жизни. В данном случае под положительной моделью самосохранительного поведения мы будем понимать действия, направленные на сохранение и продление жизни посредством ведения здорового образа жизни (физические упражнения, правильное питание, отказ от вредных привычек - курение, алкоголизм, наркомания). Под негативной моделью самосохранительного поведения подразумеваются действия, направленные на ухудшение и снижение уровня здоровья посредством ведения асоциального образа жизни (регулярное употребление алкогольных и наркотических веществ, самоубийство и др.).

Как правило, потребность в сохранении и поддержании здоровья является основопо- лагающей, она побуждает индивида к действию (например, обращение в медицинские учреждения), но в силу возрастных особенностей, общественных стереотипов (старость «естественная смерть») потребность в поддержании жизненной активности у лиц пожилого возраста может утрачиваться. Подчеркнем, что при изучении механизма формирования самосохранительного поведения у лиц пожилого возраста необходимо учитывать когнитивные установки, внутренние и внешние. Процесс формирования самосохранительного поведения включает в себя совокупность факторов и установок, которые предопределяют алгоритм социальных практик, направленных на сохранение здоровья. Как результат, индивид в процессе своей жизнедеятельности должен усвоить систему знаний и действий, касающихся поддержания здоровья. В силу современных условий, рыночных отношений ценность здоровья теряет свою первоначальную значимость и начинает рассматриваться как инструментальная ценность, которая нужна индивидам для достижения более значимых целей. Результат потребительского отношения индивида к собственному здоровью оказывает влияние, во-первых, на уровень продолжительности жизни и социальную активность, которая с возрастом снижается. Во-вторых, у индивидов различных социально-возрастных групп, в частности, у лиц пожилого возраста, не сформированы навыки ведения здорового образа жизни (правильное питание, умеренные физические нагрузки и т. д.), они привыкли пассивно полагаться на помощь учреждений здравоохранения и являться основными потребителями медицинских услуг. На наш взгляд, начиная с конца XX - начала XXI в. медицина все чаще начинает рассматриваться как рынок услуг, на котором взаимодействуют как минимум два актора: «продавец» (врач) и «потребитель» (пациент), результатом взаимодействия которых является улучшение физиологического, психологического здоровья людей. Результатом пассивного целеполагания является приобретение медицинскими учреждениями властных полномочий, а со стороны «потребителей» (пациентов) врач рассматривается как носитель знаний, способный избавить индивида от физиологических страданий. Несомненно, лица пожилого воз- 
раста являются основными потребителями медицинских услуг в силу возрастных особенностей и в большинстве случаев отсутствия знаний, касающихся сохранения здоровья.

На наш взгляд, для успешной реализации механизма формирования самосохранительного поведения и пропаганды идей здорового образа жизни следует с ранних лет формировать представления о здоровой старости и «молодеющей старости», которые будут способствовать стиранию возрастных границ; формировать комплексное представление о ведении здорового образа жизни; осуществлять активное привлечение лиц пожилого возраста к общественной жизни. Согласно положениям, рассмотренным в докладе Всемирной организации здравоохранения, для успешной пропаганды здорового старения следует:

- организовывать регулярные массовые медицинские обследования среди лиц пожилого возраста, которые могут отражать их функциональные способности, индивидуальную жизнеспособность;

- оказывать своевременную медицинскую помощь лицам пожилого возраста;

- увеличивать размер пенсионных выплат, а также сокращать стоимость услуг, которые необходимы для поддержания и сохранения здоровья [1].

Таким образом, проведенный анализ приводит нас к выводу о том, что пожилые люди являются весьма многочисленной социальной группой, к которой следует относить лиц, достигших 60 лет и старше. Начиная с трудов античных философов вопрос, связанный с особенностями феномена старости, не теряет своей актуальности и сохраняет свою значимость и на современном этапе научной мысли. Так, анализ научной литературы позволил нам выделить условно два периода в изучении сущности феномена старости: ранний (философский) и поздний (социологический).

В социологии и демографии процесс старения рассматривается как совокупность изменений, происходящих в организме и ведущих к ослаблению биологических и социальных функций индивида. Пассивное отношение к своему здоровью, неоправданные надежды на помощь учреждений здравоохранения, стереотипы, созданные средствами массовой информации, способствуют формирова- нию негативной модели самосохранительного поведения. Поэтому лица пожилого возраста нуждаются в комплексной социальной поддержке со стороны родных, социальных служб и государства, целью которых должно стать формирование устойчивых представлений о принципах здорового старения, предполагающих, что индивид, достигший пожилого возраста, будет обладать знаниями о здоровом образе жизни и вести активную социально-экономическую жизнь.

\section{СПИСОК ЛИТЕРАТУРЫ}

1. Всемирный доклад о старении и здоровье. - Электрон. текстовые дан. - Режим доступа: http://industry60plus.ru/upload/medialibrary/6cc/ 2015\%20WHO\%20report\%20in\%20Russian.pdf(дата обращения: 10.10.2016). - Загл. с экрана.

2. Журавлев, И. В. Отношение к здоровью индивида и общества / И. В. Журавлев. - М. : Наука, 2006. $-238 \mathrm{c}$.

3. Кувшинова, О. А. Проблемы социального конструкта пожилого возраста / О. А. Кувшинова // Вестник Томского государственного университета. Серия «Философия. Социология. Политология». -2012 . - № 1 (17). - С. 24-30.

4. Полькина, Т. М. Особенности понимания феномена старости на различных этапах психолого-философского осмысления / Т. М. Полькина // Вестник Башкирского университета. - 2012. № 3. - С. 1407-1412. - Электрон. текстовые дан. Режим доступа: http://cyberleninka.ru/article/n/ osobennosti-ponimaniya-fenomena-starosti-naraznyh-etapah-psihologo-filosofskogo-osmysleniya (дата обращения: 20.01.2017). - Загл. с экрана.

5. Психическое здоровье и пожилые люди. Электрон. текстовые дан. - Режим доступа: http:// www.who.int/mediacentre/factsheets/fs381/ru/ (дата обращения: 03.09.2016). - Загл. с экрана.

6. Шашок, В. Н. Старение населения как глобальная социально-психологическая проблема / В. Н. Шашок // Ученые записи Российского государственного социального университета. - 2009. № 11. - C. 22-25.

7. Щанина, Е. В. Факторы социальной активности старшего поколения / Е. В. Щанина // Известия высших учебных заведений. Поволжский регион. Серия «Общественные науки». - 2009. - № 2 (10). - С. 57-67.

8. Cumming, E. Growing old: The process of disengagement / E. Cumming, W. Henry. - N. Y. : Basic Books, 1961.-293 p.

9. Havighurst, R. J. Disengagement and patterns of aging / R. J. Havighurst, B. Neugarten, S. S. Tobin 
// Middle Age and Aging: A Reader in Social Psychology / ed. by B. Neugarten. - Chicago, IL : University of Chicago Press, 1968. - P. 161-172.

10. Longino, Ch. Explicating activity theory: A formal replication / Ch. Longino, C. Kart // Journal of Gerontology. - 1982. - Vol. 17. - P. 713-722.

\section{REFERENCES}

1. Vsemirnyy doklad o starenii $i$ zdorovye [World Report on Ageing and Health]. URL: http:// industry60plus.ru/upload/medialibrary/6cc/ 2015\%20WHO\%20report\%20in\%20Russian.pdf. (accessed October 10, 2016).

2. Zhuravlev I.V. Otnoshenie $k$ zdorovyu individa $i$ obshchestva [Attitude to Health of Individual and Society]. Moscow, Nauka Publ., 2006. $238 \mathrm{p}$.

3. Kuvshinova O.A. Problemy sotsialnogo konstrukta pozhilogo vozrasta [Problems of the Social Construct of the Elderly]. Vestnik Tomskogo gosudarstvennogo universiteta. Seriya «Filosofiya. Sotsiologiya. Politologiya», 2012, no. 1 (17), pp. 24-30.

4. Polkina T.M. Osobennosti ponimaniya fenomena starosti na razlichnykh etapakh psikhologofilosofskogo osmysleniya [A Particular Understanding of the Phenomenon of Old Age in the Different Stages of Psychological and Philosophical Understanding]. Vestnik Bashkirskogo universiteta, 2012, no. 3, pp. 1407-1412. URL: http://cyberleninka.ru/article/n/ osobennosti-ponimaniya-fenomena-starosti-naraznyh-etapah-psihologo-filosofskogo-osmysleniya. (accessed January 20, 2017).

5. Psikhicheskoe zdorovye i pozhilye lyudi [Mental Health and the Elderly]. URL: http:// www. who.int/mediacentre/factsheets/fs $381 / \mathrm{ru} /$. (accessed September 3, 2016).

6. Shashok V.N. Starenie naseleniya kak globalnaya sotsialno-psikhologicheskaya problema [Population Ageing as a Global Socio-Psychological Problem]. Uchenye zapisi Rossiyskogo gosudarstvennogo sotsialnogo universiteta, 2009, no. 11 , pp. 22-25.

7. Shchanina E.V. Faktory sotsialnoy aktivnosti starshego pokoleniya [Factors of Social Activity of the Older Generation]. Izvestiya vysshikh uchebnykh zavedeniy. Povolzhskiy region. Seriya «Obshchestvennye nauki», 2009, no. 2(10), pp. 57-67.

8. Cumming E., Henry W. Growing Old: The Process of Disengagement. New York, Basic Books, 1961.293 p.

9. Havighurst R.J., Neugarten B., Tobin S.S. Disengagement and Patterns of Aging. Neugarten B., ed. Middle Age and Aging: A Reader in Social Psychology. Chicago, IL, University of Chicago Press, 1968, pp. 161-172.

10. Longino Ch., Kart C. Explicating Activity Theory: A Formal Replication. Journal of Gerontology, 1982, no. 17, pp. 713-722.

\section{Information About the Author}

Lyubov A. Leshchenko, Postgraduate Student, Department of Philosophy and Sociology, Volgograd Institute of Management, Branch of the Russian Academy of National Economy and Public Service under the President of Russia, Gagarina St., 8, 400131 Volgograd, Russian Federation, LLA24011@yandex.ru.

\section{Информация об авторе}

Любовь Александровна Лешенко, аспирант кафедры философии и социологии, Волгоградский институт управления - филиал Российской академии народного хозяйства и государственной службы при Президенте России, ул. Гагарина, 8, 400131 г. Волгоград, Российская Федерация, LLA24011@yandex.ru. 